\title{
FRAGILIDAD FINANCIERA EN COLOMBIA Y LAS DECISIONES DE POLÍTICA MONETARIA DEL BANCO DE LA REPÚBLICA, 1996-2012*
}

Recibido: 2 de diciembre de 2014 • Aprobado: 20 de noviembre de 2015

\author{
José Mauricio Gil León ${ }^{* *}$ \\ Andrea Yaelt Lemus Vergara***
}

\section{RESUMEN}

Este artículo evalúa cuál ha sido el papel de las decisiones de política monetaria del Banco de la República dentro de los procesos de inestabilidad financiera acaecidos en Colombia en el período 1996-2012. Según la revisión de hechos, la crisis de 1999 puso en duda el papel estabilizador del banco central, lo cual reflejó una postura contra-cíclica demasiado débil para la recuperación, y la crisis de 2008 encontró un banco más preparado, aunque con respuesta tardía a los procesos emergentes de fragilidad financiera. A través de estimaciones econométricas se evidencia que una política monetaria contractiva puede inducir una crisis financiera cuando la reacción se da en momentos de mayor estrés financiero.

\section{PALABRAS CLAVE}

Ciclos económicos, política monetaria, banco central, dinero y tasas de interés

\section{CLASIFICACIÓN JEL}

E32, E47, E52

\section{CONTENIDO}

Introducción; 1. Teorías sobre fragilidad financiera; 2. Crisis financiera y política económica; 3. Efectos de la política monetaria en la fragilidad financiera; 4. Conclusiones; Bibliografía.

\footnotetext{
Este artículo es resultado de una investigación al interior del grupo de investigación OIKOS (clasificado en categoría D por Colciencias) sobre "El surgimiento de problemas de fragilidad financiera en Colombia", Universidad Pedagógica y Tecnológica de Colombia. Periodo de ejecución: 2013-2014.

-* Economista, Especialista en Finanzas y Magister en Economía de la Universidad Pedagógica y Tecnológica de Colombia, Tunja, Colombia. Docente en el área de teoría económica de la Universidad Pedagógica y Tecnológica de Colombia. Miembro del Grupo de Investigación OIKOS y EUGENE FAMA. Correo: mauricio8827@ hotmail.com.

.*. Economista, Especialista en Planeación y Gestión del Desarrollo Territorial y Magister (c) en Economía Universidad Pedagógica y Tecnológica de Colombia, Tunja, Colombia. Miembro del Grupo de Investigación OIKOS y docente catedrática de la Universidad Pedagógica y Tecnológica de Colombia. Correo: yaeljc524@hotmail. com.
} 


\section{FINANCIAL FRAGILITY IN COLOMBIA AND THE MONETARY POLICY DECISIONS TAKEN BY THE CENTRAL BANK 1996-2012}

\section{ABSTRACT}

This paper evaluates what has been the role of the monetary policy decisions taken by the Central Bank during the financial instability processes that Colombia has gone through during 1996-2012. According to the fact analysis, the 1999 crisis questioned the role of the central bank, which defended a counter-cyclic posture that was not strong enough to lead the economic recovery. The 2008 crisis found a stronger standing Central Bank, even though it answered late to the emerging processes regarding financial fragility. With the use of econometric studies it was proven that a contractive monetary policy can accelerate a financial crisis when the measure is implemented in moments when the financial stress is too high.

\section{KEY WORDS}

Economic cycles, monetary policy, central bank, money and interest rates

\section{JEL CLASSIFICATION}

E32, E47, E52

\section{CONTENT}

Introduction; 1. Financial fragility theories; 2. Financial crisis and economic policy 3. Effects of monetary policy on financial fragility; 4. Conclusions; Bibliography.

\section{FRAGILIDADE FINANCEIRA NA COLÔMBIA E AS DECISÕES DE POLÍTICA MONETÁRIA DO BANCO DA REPÚBLICA, 1996-2012 \\ RESUMO}

Este artigo avalia qual há sido o papel das decisões de política monetária do Banco da República dentro dos processos de instabilidade financeira ocorridos na Colômbia no período 1996-2012. Segundo a revisão de fatos, a crise de 1999 colocou em dúvida o papel estabilizador do banco central, o qual refletiu uma postura contra-cíclica demasiado fraca para a recuperação, e a crise de 2008 encontrou um banco mais preparado, porém com resposta tardia aos processos emergentes de fragilidade financeira. Através de estimações econométricas se evidencia que uma política monetária contrativa pode induzir uma crise financeira quando a reação se dá em momentos de maior estresse financeiro.

\section{PALAVRAS CHAVE}

Ciclos económicos, política monetária, banco central, dinheiro e taxas de juros

\section{CLASSIFICAÇÃO JEL}

\section{E32, E47, E52}

\section{CONTEÚDO}

Introdução; 1. Teorias sobre fragilidade financeira; 2. Crise financeira e política económica; 3. Efeitos da política monetária na fragilidade financeira; 4. Conclusões; Bibliografia. 


\section{INTRODUCCIÓN}

Por efecto de las crisis recurrentes entre 1980 y 2010 el tema de la estabilidad financiera se ha convertido en uno de los objetivos de análisis para la política económica, y son algunos bancos centrales y varias instituciones financieras internacionales (FMI, Banco Mundial y Banco Internacional de Pagos) las que a través de informes periódicos muestran interés en monitorear variables relacionadas con la estabilidad financiera. Según Schinasi (2005) un sistema financiero es estable cuando: 1) se facilita la asignación eficaz de los recursos económicos entre ahorro e inversión, préstamo y endeudamiento, creación y distribución de liquidez, fijación de los precios de los activos, acumulación de la riqueza y crecimiento de la producción; 2) es capaz de valorar, asignar y gestionar los riesgos financieros y; 3) cumple las funciones señaladas ante desequilibrios y choques externos. Con estabilidad financiera no se espera que todas las partes del sistema financiero funcionen al máximo en todo momento; sin embargo, este sistema es capaz de resolver de forma automática los desequilibrios antes de desencadenar una crisis y llevar a perturbar las funciones del dinero (medio de pago, unidad de cuenta y depósito de valor).

Es común que para identificar las crisis en las economías emergentes se reflejan algunos hechos en períodos anteriores a la detonación de una crisis, Borio y Lowe (2002), Christiano y otros (2010) y Reinhart y Reinhart (2009) señalan que el patrón más común son los auges en el crédito (booms crediticios), el surgimiento de burbujas en el mercado de activos y una excesiva entrada de capitales. Cuando llega el momento de la crisis la producción de la economía cae de manera abrupta, se presenta una desvalorización de las acciones y viviendas, encadenándose con una parada en el crédito (credit crunch), y una salida masiva de capitales (sudden stop).

En medio de las consecuencias de la crisis financiera de 2008 la discusión sobre la participación que tiene la estabilidad financiera en las decisiones de política monetaria tiene una mayor relevancia, y en las economías latinoamericanas esta discusión aparece después de que las autoridades económicas desde la década de los noventa tuvieran una elevada aversión a la inflación. Por tanto, países como Colombia asumieron el compromiso de mantener el poder adquisitivo de los hogares (por el costo en bienestar generado por la inflación), el cual es definido por el mandato constitucional dado al Banco de la República en 1991, y que se refuerza a partir de 1999 cuando se adopta el esquema de inflación objetivo, que garantizaría una estabilidad de precios a largo plazo. Para lograrlo la política del banco debe ser transparente y, de esa manera, la meta sea creíble.

No obstante, Colombia por su carácter de economía emergente se encuentra expuesta a vulnerabilidades que se asocian a bonanzas de flujos de capital que 
generan incrementos en los precios de los activos, crecimiento excesivo del crédito, que sin una regulación financiera adecuada puede llevar a procesos de inestabilidad financiera. Este esquema es el que describe los orígenes de la crisis de finales de la década de los noventa, y llevó a que entidades financieras y autoridades económicas tomaran medidas que incrementaron la represión financiera.

En ese sentido, el objetivo de este artículo es evaluar el papel de las decisiones de la autoridad monetaria en la dinámica de la estabilidad financiera, entre 1996 y 2012 (periodo en el que se presentaron dos situaciones de estrés financiero, una a finales de la década de los noventa y otra entre 2008 y 2009 en medio de la crisis financiera internacional). Bajo algunas consideraciones se analiza la respuesta del Banco de la República a dicha estabilidad, aunque resulta necesario aclarar que no existe una definición explícita sobre la intervención en variables asociadas a la fragilidad financiera; sin embargo, dentro de las variables que se buscan controlar para la previsión de la inflación se encuentran variables financieras como: el crecimiento del crédito, la cartera vencida, el comportamiento de los precios de los activos, etc. Por lo anterior, resulta interesante comprender si ha existido un compromiso implícito por parte de la autoridad monetaria en evitar desequilibrios financieros. Para comprobar esto se recurre a la estimación de un VAR (Vectores AutoRegresivos) con datos trimestrales, en donde es posible detectar la dinámica de la interrelación entre variables asociadas a la política monetaria, la estabilidad financiera y la estabilidad económica, y a través de las funciones impulso-respuesta detectar el rezago en la transmisión de diferentes choques. Estas relaciones dinámicas se analizan sin considerar una forma estructural, pero la necesidad de entender el comportamiento del estrés financiero lleva a definirla y estimarla mediante el Método Generalizado de Momentos (MGM).

Este documento se divide en cuatro secciones, sin incluir la introducción. La primera presenta una revisión teórica sobre fragilidad financiera, y para esto se revisan tres tipos de modelos que explican la generación de una crisis financiera. La segunda de las secciones se enfoca en explicar las decisiones de la política monetaria del Banco de la República en momentos de fragilidad financiera. En la tercera sección se analizan los efectos de las decisiones de política monetaria sobre la fragilidad financiera, donde se expone una revisión teórica y empírica del tema; además, se realizan estimaciones econométricas, con datos trimestrales para Colombia, y se comprueba la relación dinámica entre la inestabilidad financiera, las decisiones de política monetaria, el ciclo económico y el comportamiento de los flujos de capital. Por último, se presenta las conclusiones sobre las particularidades identificadas en el análisis. 


\section{TEORÍAS SOBRE FRAGILIDAD FINANCIERA}

Según Reinhart y Rogoff (2011) los procesos de inestabilidad financiera que se engendran en las distintas economías son generados por crisis de distinto tipo: cambiarias, de deuda, bancarias, inflacionarias y de balanza de pagos. Un trabajo en el que se hace un diagnóstico de las causas y consecuencias de las diferentes crisis durante los últimos ocho siglos es el de Reinhart y Rogoff (2011), en el que se exponen los elementos distintivos de cada tipo de crisis, los países en los que ocurrieron y los periodos del suceso. Los resultados del estudio muestran que en una gran parte de los países las crisis (inflacionarias y cambiarias) tuvieron menos efectos, dado que implementaron tasas de cambio flotantes y una política monetaria enfocada en el control de la inflación, pero las crisis bancarias y de deuda son todavía una realidad y las autoridades deben implementar herramientas de política e indicadores de alerta temprana para prevenirlas.

De acuerdo con Cerón (2008) y Castro (2011), desde el punto de vista teórico, existen tres grupos de modelos explicativos de las crisis financieras.

En el primer grupo de modelos la inestabilidad ocurre por los fundamentales y las expectativas generadas, siendo el detonador de la crisis un choque exógeno. Dentro de estos modelos están los de primera generación donde las principales formulaciones son de Krugman (1979) y Flood y Garber (1984), y los de segunda generación con la formulaciones de Obstfeld (1996) y Calvo y Mendoza (1998). Para el caso de los primeros, el gobierno es el principal responsable de la crisis por buscar objetivos internos y externos incompatibles, ya que bajo un tipo de cambio fijo busca financiar el déficit fiscal con emisión monetaria (es el problema de la trinidad imposible de la política económica'). El choque exógeno comienza con la expansión monetaria realizada por el banco central, donde al tratar de esterilizar los efectos agota las reservas internacionales y lleva a un ataque especulativo.

En los modelos de segunda generación la inestabilidad surge por unas expectativas de los inversionistas que van en contra de lo que realizan las autoridades (credibilidad del banco central, tasas de cambios estables, bajas tasas de interés, etc.), a pesar que no exista alguna deficiencia en la economía los agentes actúan a partir de rumores existentes que debilitan la confianza en mantener las posiciones de inversión. La consecuencia es una salida masiva e inesperada de capitales inter-

La trinidad imposible de la política económica o la imposibilidad de Mundell surge cuando con perfecta movilidad internacional de capitales no es posible tener al mismo tiempo un control de la tasa de cambio y una política monetaria autónoma; por tanto, se debe sacrificar una de las políticas, la monetaria o la cambiaria. Estos casos los muestra Reinhart y Rogoff (2011) en los países de América Latina durante la década de los ochenta. 
nacionales (paradas súbitas²) que generan un problema cambiario y de financiación a la economía.

En el segundo grupo de modelos la inestabilidad surge por la estructura de las hojas de balance, creándose ciclos endógenos en donde el detonador de la crisis es un choque endógeno. Aquí surgen modelos heterodoxos como los de Minsky (1982) y Kalecki (1956), los cuales se aplican a economías cerradas y desarrolladas. Minsky (1982) en su hipótesis de inestabilidad financiera (HIF) tuvo interés en entender los ciclos económicos desde un enfoque de fragilidad financiera para comprender el origen de las crisis financieras (Kurczyn, 1997). La HIF partió de mostrar que estas surgen de un entorno de inestabilidad financiera endógena al sistema económico, y termina por describir las consecuencias sobre la evolución de la economía.

Para Minsky (1982) la HIF muestra la importancia de la deuda y las estructuras pasivas en la determinación de la inversión, dado que en condiciones de alto crecimiento económico se favorecen las expectativas de inversión apalancada con crédito. A medida que el auge continúe las expectativas optimistas aumentan y surge una presión al alza en los precios de los activos, los cuales terminan sobrevaluados (el precio del activo se encuentra por encima del precio explicado por los fundamentales) y los agentes sobre-endeudados (se transforma el financiamiento en tipo Ponzi ${ }^{3}$ debido a que los flujos de caja de las empresas y de las familias no pueden cubrir las deudas). Con esta nueva situación hay una reversión en las expectativas hacia un sentido pesimista, los activos comienzan a ser liquidados, y esto crea a un período de deflación, para luego conducir a la economía a una contracción de la inversión y de la demanda agregada.

Desde este mismo enfoque Kindleberger (1989) amplía la explicación que hace Minsky (1982) sobre la fragilidad financiera, dado que si en medio del auge económico se encuentra que los rendimientos de los activos son más altos que los de las inversiones productivas, la solicitud de créditos para adquirirlos aumenta, y esto seguirá por más que los bancos exijan mayores intereses. Si los especuladores que toman esta conducta son bastantes, las expectativas se cumplirán porque las cotizaciones de los activos serán cada vez mayores. Es entonces que el choque engendrador de la inestabilidad será el suceso más inofensivo e inesperado que pueda estar relacionado con el proceso especulativo, y como señala Gil (2010) esto lleva a que los precios de los activos desciendan y se generalice el pánico financiero.

2 Problema que Reinhart y Rogoff (2011) evidenciaron en Tailandia, Rusia, Brasil y Colombia a finales de la década de los noventa.

3 Financiamiento del pago de una deuda a través de otra deuda. 
Otro de los modelos es el de Kalecki (1956), el cual sustenta que la inestabilidad surge del efecto que tiene la tasa ganancia y el cambio en el acervo de capital sobre la tasa de ganancia del siguiente periodo; siendo entonces una forma de expresar que la inversión afecta con rezago a la ganancia y, de esta manera, a la formación de movimientos cíclicos. En ese sentido, cuando la inversión de la empresa aumenta, y esta es financiada con crédito, con una tasa de ganancia creciente el apalancamiento será cada vez mayor, pero si la tasa de ganancia cae las decisiones de inversión disminuyen; pero por el tamaño del endeudamiento de las empresas surge la fragilidad financiera y cuando se dan los incumplimientos en los pagos empezará un periodo de retroceso en la economía.

En el tercer grupo de modelos la inestabilidad surge de las hojas de balance y la crisis detona por un choque exógeno. Dentro de este grupo se pueden clasificar tres tipos de modelos: modelos basados en la teoría de Minsky, pero que considera el papel de los flujos de capital, los tipos de cambio y las tasas de interés externas como generadores de la crisis como los expuestos por Kregel (1998), Arestis y Glickman (2002) y Ocampo (2003); los modelos basados en Krugman (1999), que consideran el efecto del estado de las hojas del balance, donde el detonante son los flujos de capital, el tipo de cambio y las tasas de interés externas (conocidos como modelos de tercera generación); y los modelos de Caballero y Krishnamurthy (2000) y Mishkin (2007) basados en las crisis bancarias donde los problemas de información asimétrica tienen un papel crucial.

Desde la teoría de Minsky (1982) la crisis en una economía abierta llega antes que en una economía cerrada, y respecto a ello Kregel (1998) explica la crisis del sudeste asiático, y expone que cuando la crisis se acentúa, la inexistencia de un spread de tasas de interés apropiado genera una salida masiva de capitales y la devaluación de la moneda nacional, el efecto de las tasas de interés en los flujos de efectivo se profundiza, y más aún si la política interna es proteger el tipo cambio con un aumento en las tasas de interés. Este planteamiento lleva a sugerir a la autoridad monetaria su intervención mediante las reservas internacionales y los controles de capital como instrumentos de política, por tanto el banco central tiene que acumular reservas internacionales para elevar la razón de estas respecto a la deuda en moneda extranjera, para colocar al país en una denominación de financiamiento cubierto, pero propensa a volverse especulativa con una variación en el tipo de cambio. Como señala Melo (2012), la especulación surge porque los inversionistas internacionales consideran que el monto de reservas internacionales está bajando y eleva la presión cambiaria, por lo que la economía transita hacia una situación Ponzi.

Según Arestis y Glickman (2002) la transmisión de la crisis cambiaria al interior ocurre cuando el financiamiento externo se agota y los agentes financian el pago de la 
deuda con más deuda, y esto a la vez lleva a una venta de emergencia de existencias y de bienes de capital. Lo anterior crea una caída en los precios de los activos y un deterioro en la cartera de los prestamistas y de los prestatarios, incluso los que no han tenido financiamiento con moneda extranjera. En ese sentido, según Ocampo (2003) existe el debate de la debilidad del instrumento de reservas internacionales, por lo que se sugiere el control de capitales para favorecer la posición de liquidez en moneda extranjera del banco central, siendo unas medidas anti-cíclicas porque reducen el crecimiento de la cartera especulativa en momentos del auge. Los controles pueden ser de dos tipos: los controles basados en precios como el impuesto a los movimientos internacionales de capital, denominado como tasa Tobin, y los encajes; y los controles cuantitativos, basados en restricciones y plazos, o restricción sobre el tipo de activos que pueden ser adquiridos.

En los modelos de tercera generación, expuestos por Castro (2011), la fragilidad financiera surge de manera endógena del proceso de expansión del nivel de endeudamiento y, de esta manera, surge un mayor riesgo mientras la deuda se concentra en moneda extranjera y las importaciones tienen alta dependencia al ciclo económico interno. Por tanto, según Krugman (1999) la reversión en los flujos de capital afectará de forma negativa a las hojas de balance de las empresas domésticas, y ocasionará una menor posibilidad de endeudamiento y menores flujos de caja. En este tipo de modelos aparece la noción de las crisis gemelas, donde la crisis cambiaria junto a la crisis bancaria son evaluadas de forma empírica por Reinhart y Reinhart (2009), quienes analizan el papel de las bonanzas de flujos de capital en la generación de crisis financieras en economías avanzadas y emergentes desde 1980 a 2007, y encuentran que en países emergentes a las bonanzas le siguen periodos de crecimiento económico lento y un descenso en los precios de los activos (vivienda y acciones).

Como lo muestra Caballero y Krishnamurthy (2000) en estos últimos modelos la inestabilidad es consecuencia de la asimetría de la información, siendo que el exceso de crédito en la economía incrementa la tasa de interés interna, lo que ocasiona una disminución en los precios de los activos, y esto trae consigo problemas para los bancos y una profundización de la crisis. Mishkin (2001) describe que los choques que extienden la inestabilidad son: el deterioro de las hojas de balance del sector financiero (pérdidas por el exceso de apalancamiento), el aumento en tasa de interés (menor liquidez), la mayor incertidumbre y el deterioro de las hojas de balance de las empresas no financieras.

\section{CRISIS FINANCIERA Y POLÍTICA MONETARIA EN COLOMBIA}

Desde la década de 1990 se observan dos ciclos en los que se evidencia una clara relación entre el sector real con el ciclo del crédito, el comportamiento de los precios 
de los activos y la dinámica de los flujos de capital. El primero transcurre entre el inicio de la apertura económica y la salida de la recesión de finales de los noventa, y el segundo se ubica entre la recuperación de la economía colombiana después de 2002 hasta el 2012 cuando algunos países de Europa y Estados Unidos tratan de salir de la crisis.

\subsection{Crisis de los noventa y política monetaria}

El primer ciclo inicia en la década de los noventa cuando surge un dinamismo por el mayor acceso al financiamiento externo, gracias a la apertura de los capitales, que permitió el crecimiento de la deuda pública y privada. La liquidez venia definida en flujos internacionales de capital, tanto de largo como de corto plazo, y los choques que estos pudieran tener afectarían al financiamiento de la economía, y por su carácter pro-cíclico serian una fuente de riesgo para la estabilidad financiera.

No obstante, la incertidumbre surgida en los países emergentes entre 1997 y 1999 llevó a una salida masivas de capitales (paradas súbitas), siendo Tailandia el epicentro de la inestabilidad surgida (sufre una fuerte crisis cambiaria y de deuda), que se traslada a Rusia (surge una situación de incumplimiento de los pagos de la deuda) y luego contagia a las economías latinoamericanas como Brasil y Colombia. En este último, el contagio llevó a una parada súbita en 1998, que ocasionó el aumento en la prima de riesgo y que tuvo como consecuencia una mayor restricción al financiamiento externo.

Según López y Salamanca (2009) y Cárdenas y Badel (2003) los hechos señalados indujeron a que el precio de la vivienda descendiera y que el valor de la deuda aumentara. Además, se suma un aumento de la carga financiera de los hogares debido a que desde 1996 hubo un aumento continuo de las tasas de interés. La elevada carga financiera a finales de la década de los noventa incidió en el deterioro de la calidad de la cartera, siendo la de consumo la primera en deteriorarse, y seguida por la cartera hipotecaria que terminaría por acelerar la crisis. Con los resultados de la calidad de la cartera, la solvencia y la rentabilidad del sistema financiero fue posible que el Banco de la República creara un indicador de estrés financiero 4 , donde es evidente en el gráfico 1 que a partir de septiembre de 1998 hasta abril de 2002 ocurre el mayor nivel de estrés financiero en la economía colombiana.

4 Indicador construido por el departamento de estabilidad financiera del Banco de la República con datos de la superintendencia financiera. El indicador considera el ROA (rentabilidad sobre los activos), ROE (rentabilidad sobre el patrimonio), la cartera vencida respecto a la cartera total, la cartera improductiva respecto a la cartera total, el margen de intermediación ex - post, los pasivos líquidos sobre activos, los fondos interbancarios sobre activos líquidos, la razón de pasivos no cubiertos y el número de entidades bajo un alto nivel de estrés. 
Gráfico 1. Índice de estrés financiero del Banco de la República

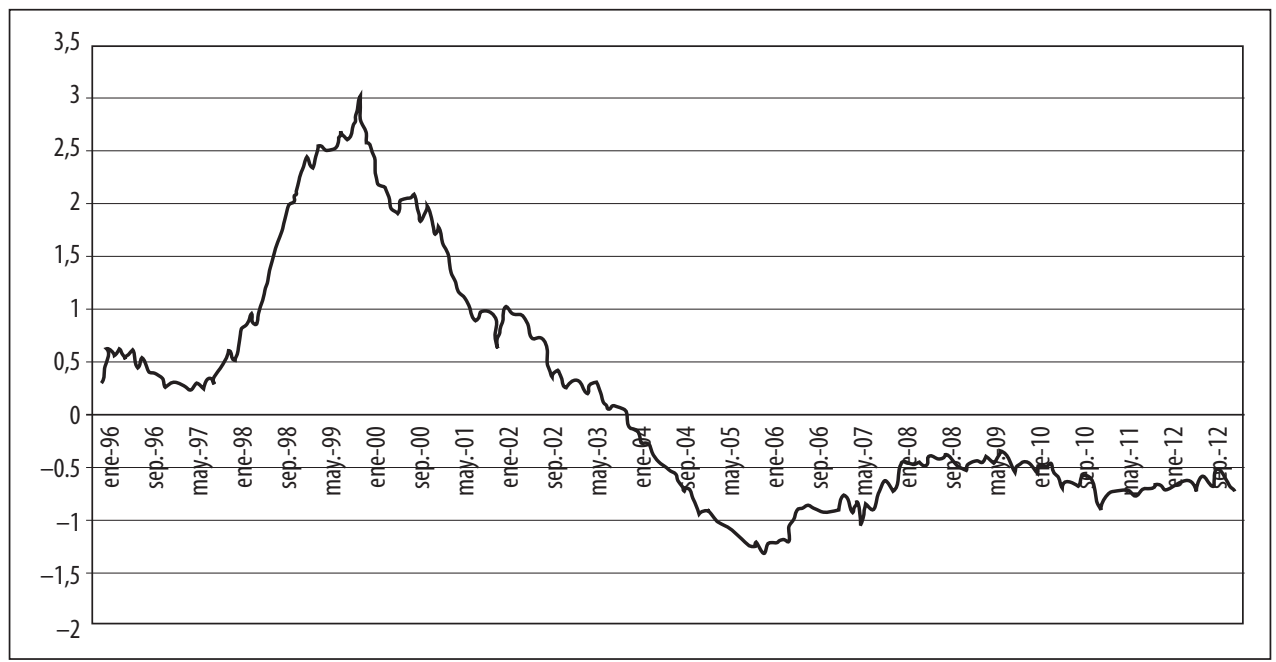

Fuente: elaboración propia con datos del Banco de la República (2014)

La postura de la política monetaria en la crisis se analiza de acuerdo al comportamiento de la brecha del $\mathrm{Ml}^{5}$, suponiendo que toda expansión monetaria se refiere a un resultado positivo y toda contracción a un resultado negativo. En el gráfico 2 se evidencia que desde enero de 1997 hasta mayo de 1998 ocurre una expansión monetaria, que responde a la desaceleración de 1997, pero la intervención pasiva de la autoridad monetaria lleva a la aparición de una contracción.

Según Echeverry (2001), la respuesta de la política económica en 1997 motivó la formación de una burbuja de la actividad económica entre 1997 y principios de 1998, y por ello es que colocó a la economía en el abismo de un ataque cambiario, y para evitarlo tuvo que elevar las tasas de interés que atrajera capital extranjero. Esta afirmación coincide con Echavarría, González y Rodríguez (2012), que contrastan la estimación de una regla de Taylor simple con la tasa de política observada, y encuentran que entre el segundo trimestre de 1999 y el cuarto trimestre del 2000 el Banco de la República tuvo una postura demasiado contractiva.

5 Para construir la brecha del M1 se sigue los siguientes pasos: 1. Se deflactan la series a través del IPC base diciembre de 2012; 2. Se desestacionalizan las series mediante el X-12 ARIMA; 3. Se obtiene la tendencia de largo plazo con el filtro de Hodrick-Prescott entre 1996 y 2012 y; 3. Se calcula la brecha tomando la diferencia entre logaritmo natural de cada dato y el logaritmo natural de la tendencia de largo plazo. 
Gráfico 2. Brecha del agregado monetario M1

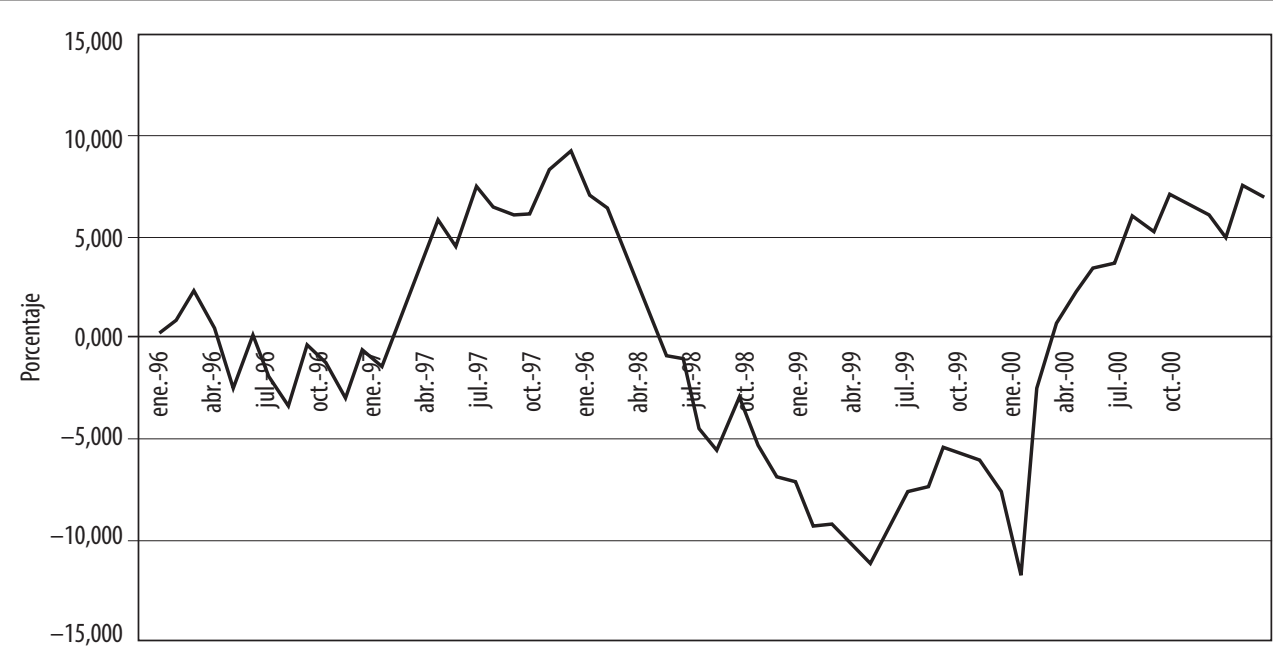

Fuente: elaboración propia con datos del Banco de la República (2014)

En ese sentido, para González (1999) la perversidad de la política monetaria surge con la adopción de un régimen de política monetaria con metas de inflación y el compromiso de mantener el precio del dólar dentro de una banda junto a una apertura de capitales, debido que la abundante entrada de dólares entre 1990 y 1997 creo dificultades en el direccionamiento de la política monetaria. La abundante entrada de dólares causó problemas a la autoridad monetaria porque: generó presiones sobre la cantidad de dinero ${ }^{6}$, impulsó el aumento en la tasa de interés ${ }^{7}$ y revaluó el peso colombiano ${ }^{8}$. Según Hernández y Tolosa (2001), los problemas surgieron por el esquema de política monetaria tan complejo que se manejaba en ese momento, debido a que combinaban corredores monetarios, corredores de tasas de interés de intervención y corredores cambiarios.

Sin embargo, en el informe de la Junta Directiva del Banco de la República de marzo de 2000 se hizo referencia al perfil expansivo de la política monetaria desde octubre de 1998 cuando se incrementó la liquidez en la economía, dado que la base

6 Los poseedores de dólares monetizaban pero el Banco de la República se obligó a realizar operaciones de esterilización a través de la venta de bonos que reducía la cantidad de dinero.

7 La disminución de la cantidad de dinero eleva la tasa de interés, y esto se demuestra con el aumento de la tasa de interés real que en promedio fue de $20 \%$, mientras que la tasa internacional era cercana a $7 \%$.

8 La entrada de dólares creaba tendencia a la revaluación y con un diferencial de tasas más alto presionaba a que entraran aún más dólares a la economía colombiana. 
monetaria retornó al interior del corredor monetario observándose un crecimiento de 23,6\% desde finales de 1998 hasta finales de 1999, resultado superior en 8,3\% al crecimiento previsto para el PIB nominal (15\%); en ese sentido, por el decrecimiento del PIB real de 4,2\% en 1999 y una inflación observada de 10\% para la autoridad monetaria es una expansión monetaria mayor que la buscada, lo cual contribuiría a la reactivación de la actividad económica. No obstante, si se compara el crecimiento de los corredores con la tendencia de largo plazo de los agregados monetarios fue una persistente contracción, debido a que la defensa a la banda cambiaria y a la meta de inflación en 1998 fue demasiado agresiva?.

\subsection{Recuperación de la economía y crisis financiera internacional}

La disminución estructural de la inflación en la década del 2000 permitió la adopción de una política monetaria más expansiva por parte del Banco de la República; sin embargo, en el mercado de crédito la respuesta no se dio de la misma manera debido a la mayor concentración del sistema bancario por la liquidación y fusión de los bancos y por la mayor aversión al riesgo de los mismos. En ese sentido, la recuperación financiera ocurre desde septiembre de 2002 cuando se detuvo la caída de la participación de la cartera en el PIB (en junio de 2001 la participación cae a su nivel más bajo de 20,48\% y en el siguiente trimestre aumenta a 20,69\%), y así sigue hasta marzo de 2006 cuando la recuperación se transformó en un alto crecimiento relacionado con el mayor crecimiento económico y llevó a que la cartera fuera cercana a 32\% en diciembre de 2008. Sin embargo, por la crisis financiera internacional y por las mayores restricciones de política monetaria el crecimiento de la cartera se ve disminuido, aunque en el 2010 vuelve a tomar aliento y llevó a la economía en diciembre de 2012 a una profundización financiera de 38\%.

En relación al riesgo de la cartera se observa en el gráfico 1 que el índice de estrés financiero disminuye a niveles negativos. El descenso ocurre desde 2004 y la estabilidad perdura durante todo el período en el que se extiende la gráfica. La explicación se da por la disminución en el indicador de mora, dado que antes de 2003 este se encontraba en niveles de dos dígitos y desde junio de 2004 este mismo se encontró en niveles inferiores al $8 \%$, y en especial se da por el descenso en la cartera hipotecaria vencida (encontró un nivel mínimo de 3,3\% en diciembre de 2006). No obstante, por el auge económico la cartera de consumo comenzó a crecer

9 Según Fernández (2003) la fuerte reacción de defensa a la banda cambiaria fue una medida en contra de la inflación, la cual tuvo su resurgimiento en 1998 junto con dos ataques cambiarios. El primer ataque cambiario ocurrió a principios de 1998, y el Banco lo combatió a través de una política de venta de reservas que se trató de esterilizar, pero lo que alimentó fue un segundo ataque especulativo a mediados del mismo año por el efecto de compensación, y por esta razón la siguiente intervención realizada fue no esterilizada, que llevó a la excesiva contracción monetaria. 
por encima del crecimiento del PIB, por lo que la carga financiera de los hogares en 2008 fue de 13\% y el riesgo se modificó hacia una tendencia ascendente, que se tradujo en un ligero crecimiento de la cartera vencida y, de esa manera, alertó al sistema financiero de un crecimiento en el riesgo del crédito. El indicador de mora vuelve a niveles bajos en septiembre de 2010, cuando es inferior a 4\%, después que comenzara el contagio de la crisis a nivel mundial.

Cuando la crisis internacional comienza (2007 y 2008), el comportamiento del valor real del IGBC (Índice General de la Bolsa de Valores de Colombia) se puede clasificar en tres periodos: durante los tres primeros trimestres de 2007 cae 10,7\%, entre diciembre de 2007 y marzo de 2008 desciende 18,86\% y desde octubre hasta diciembre de 2008 desciende 19,12\%. Entre las razones que explicaron el descenso de los precios de los activos financieros fue la salida masiva de capitales de corto plazo, reflejándose en un saldo negativo de U\$3.800 millones de dólares entre diciembre de 2007 hasta septiembre de 2009 y en el precio del dólar que superó los \$2000 pesos colombianos desde diciembre de 2008 hasta septiembre de 2009.

El comportamiento del precio de la vivienda durante años después de la crisis de fin de siglo fue de tendencia ascendente, en especial, después de diciembre de 2004, reflejado en una recuperación de la cartera hipotecaria (desde junio de 2004 comienza a tener mayor participación dentro del PIB). El mayor crecimiento de la cartera de vivienda y del precio de la misma ocurre entre 2006 y 2007, que por la crisis internacional se detiene y se estabiliza en la tendencia, siendo a mediados de 2010 el periodo en que se revitaliza el crecimiento del precio aunque con continuas correcciones. En ese sentido, el consolidado es que la crisis de 2008 no vulneró la estabilidad financiera de la economía colombiana por un estrés financiero que se mantuvo en niveles bajos.

No obstante, la autoridad monetaria colombiana tuvo una respuesta a los riesgos que podrían causar la crisis internacional, y por ello a finales de 2008 baja la tasa de interés a pesar del incumplimiento de la meta de inflación. Además del descenso de la actividad económica y de la inflación, el auge del crédito se detuvo, siendo una razón adicional para realizar la expansión monetaria y evitar el surgimiento de brotes de inestabilidad financiera. En los meses posteriores la tasa de interés disminuyó hasta 3,25\% (marzo de 2013), mientras que la actividad económica se recuperó y el crédito tuvo un crecimiento superior a la tendencia.

Después de 2007, por la incertidumbre en la economía mundial se adoptaron distintas medidas de tipo macro-prudencial, y entre ellas se encuentran: 1. Establecimiento de un encaje marginal en moneda nacional a instituciones financieras; 2. Un 
depósito de $40 \%$ durante seis meses a los créditos en moneda extranjera realizados por firmas del sector real; 3. El Ministerio de Hacienda estableció un depósito de 40\% y por seis meses a la inversión extranjera de portafolio; 4. A mediados de 2012 se reforzó la regulación exigiéndose un capital superior al 4,5\% de los activos ponderados de acuerdo al riesgo, con excepción de los activos no líquidos (bienes raíces). Estas medidas suavizaron los efectos de la crisis internacional y permitieron que desde 2009 la calidad de la cartera del sistema financiero mejorara y el crecimiento del crédito se moderara (Zárate, León y Gómez, 2012). No obstante, el riesgo latente se encuentra en la incertidumbre causada por lo que pueda ocurrir en los mercados financieros europeos y en la postura de la FED de elevar las tasas de interés.

\section{EFECTOS DE LA POLÍTICA MONETARIA EN LA FRAGILIDAD FINANCIERA}

\subsection{Revisión teórica y empírica}

La tasa de interés de política refleja el costo del apalancamiento en la economía y es un determinante para las restricciones de fondeo de los intermediarios financieros y de los precios de los activos. El costo de apalancamiento genera la existencia de restricciones por costos en los créditos interbancarios, y de esa manera, en los costos para hacer inversión y para consumir,

Una primera aproximación a la relación entre el costo de apalancamiento y las decisiones de inversión son las proposiciones de Modigliani y Miller (1958), donde la fuente de financiamiento de los proyectos de inversión es independiente a las decisiones de inversión y al valor de la empresa, de acuerdo a los supuestos de una economía con perfecta información, y con costos de transacción y costos de monitoreo nulos. No obstante, Mies, Morandé y Tapia (2003) muestra que la existencia de los intermediarios como los bancos lleva a la aparición de problemas de asimetría de la información entre los prestamistas y los prestatarios, junto a los costos de transacción, problemas de agencia, y riesgos de liquidez. En ese sentido, como lo analiza Bernanke, Gertler y Gilchrist (1998) y Tenjo y otros (2007) al existir los problemas mencionados los costos de financiamiento externos (ampliación de los pasivos) terminan siendo más altos que los costos de financiamiento interno (ampliación del patrimonio).

En ese sentido, según Kiyotaki y Moore (1997) y Bernanke, Gertler y Gilchrist (1998) las decisiones de política monetaria llevarán a que las empresas y los hogares vean alterado su flujo de efectivo. Una disminución en la tasa de política llevará a que disminuyan los costos marginales de asignación de créditos, por la disminución de las tasas de captación, y aumenten los precios de los activos y de esta manera se flexibilice el acceso al financiamiento externo. No obstante, este crecimiento 
del volumen de crédito puede llevar a excesos de endeudamiento que en un futuro pueden deteriorar la posición patrimonial de los agentes. En este mismo caso, si la tasa de política disminuye hasta ser inferior a la tasa natural, se induce a la toma excesiva de riesgos que puede conducir a un proceso de inestabilidad financiera. Desde una situación contraria, un aumento de la tasa de interés de política aumenta los costos marginales de los créditos y disminuye el valor de los activos, lo cual dificulta el acceso a fondos propios, debido a que el menor valor del colateral lleva a que los bancos tiendan a exigir mayores tasas y/o racionen el crédito).

La evidencia empírica muestra una conexión entre las decisiones de política monetaria y la estabilidad financiera a través del crecimiento de la hoja de balance de los bancos, Un documento destacado es el Adrian y Shin (2008), quienes muestran que la disposición y la capacidad de los intermediarios financieros para tomar riesgo a la hora de realizar los préstamos dependen de factores adicionales a la política monetaria, como es caso del comportamiento de los intermediarios frente al ciclo económico y la capacidad instalada para realizar la oferta de crédito. Sin embargo, la tasa de interés de corto plazo incide en los costos de apalancamiento y es relevante para la hoja de balance de los intermediarios financieros, la cual tiene un alto crecimiento a medida que la tasa de interés es baja y se transforma en lento cuando la tasa de interés aumenta. En ese sentido, se considera que la política monetaria puede anticipar los efectos potenciales de las distorsiones generadas por el apalancamiento, por lo que se deduce la fuerte conexión entre la política monetaria y la estabilidad financiera.

En Colombia Tenjo y otros (2013) con una muestra mensual entre 1994 y 2012 para 13 bancos evidencia la existencia de una relación positiva entre el crecimiento de la cartera de crédito y el ciclo económico, reafirmándose lo señalado. El análisis del comportamiento pro-cíclico parte de la dinámica de los activos y la composición de los pasivos, donde el incremento en los créditos es financiado con un aumento en los denominados pasivos no básicos (pasivos con otros bancos y con bancos extranjeros), debido a las favorables perspectivas frente a la valorización del capital y la reducción del precio del riesgo; siendo esto un argumento esencial para comprender la vulnerabilidad y el riesgo sistémico en el mercado financiero colombiano. En el mismo estudio se encuentra que la respuesta del crecimiento del crédito a la postura de la política monetaria es negativa, por lo que una expansión monetaria lleva a que los bancos decidan ampliar el crédito financiado en parte por los pasivos no básicos (no son significativamente importantes), y una contracción monetaria puede detener el surgimiento de algún boom crediticio.

Lo anterior se puede sintetizar en el esquema 1, en donde se observa que una decisión de política monetaria se transmite al crédito según el riesgo que estén 
dispuestos a tomar los intermediarios financieros. La percepción del riesgo de estos intermediarios depende de su aversión al riesgo, de las características del sistema financiero, de la regulación a las actividades financieras y de la supervisión existente; donde esto define la administración que se tendrá en la hoja de balance; es decir, se considera el tamaño óptimo de los activos, la composición de la fuente financiamiento entre pasivos y patrimonio, y el grado apalancamiento que tiene (pasivos respecto al patrimonio). Estas características llevan a explicar la expansión del crédito cuando disminuye la tasa de interés de política. El resultado son dos tipos de efectos: la inflación y la actividad económica, y la estabilidad financiera. El primero llega por la demanda impulsada por el crédito; y el segundo por el tamaño del crédito respecto al ingreso, la calidad del mismo y las características de la hoja de balance de los intermediarios financieros.

Esquema 1. Transmisión de la política monetaria a la estabilidad financiera

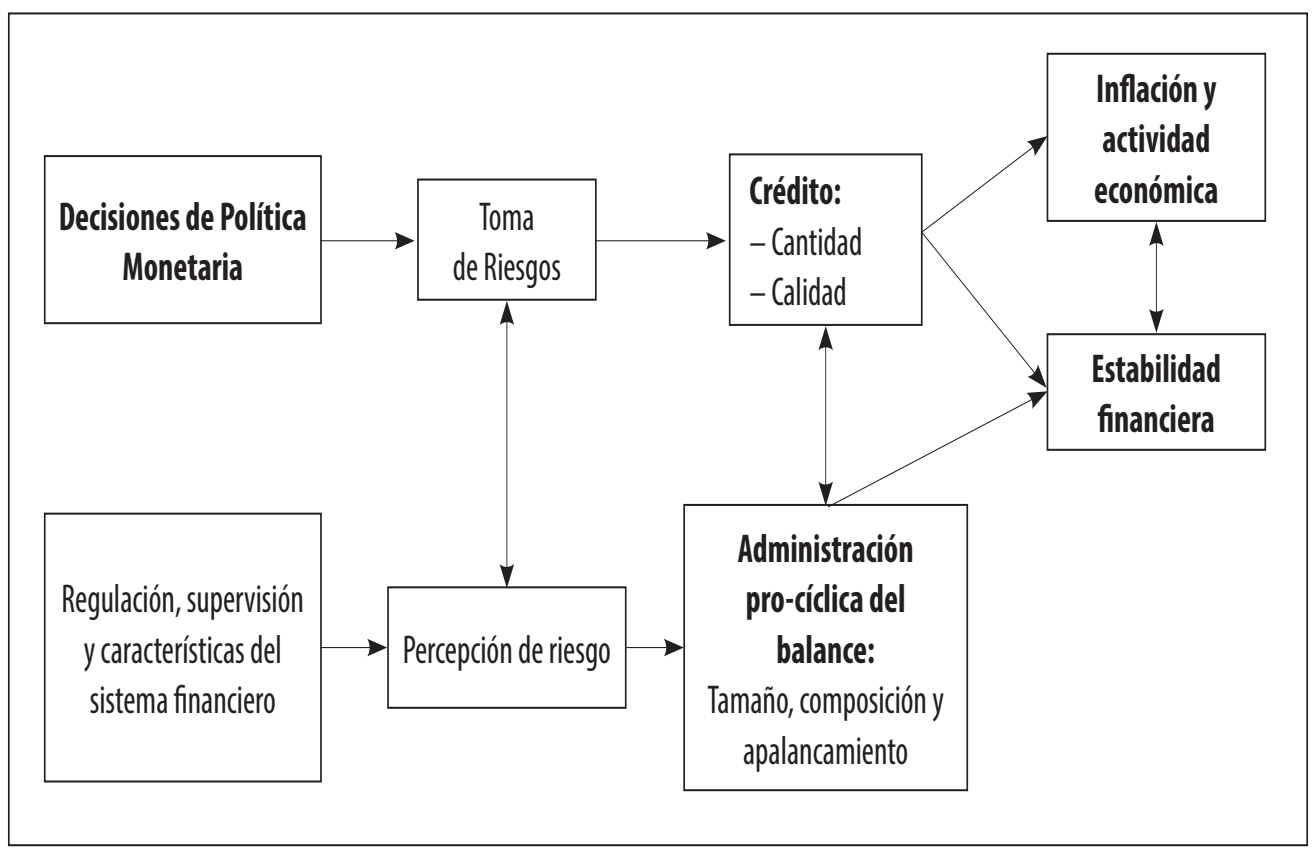

Fuente: figura adaptada de la presentación de Tenjo (2013)

\subsection{Estrategia empírica}

La estrategia empírica utilizada para determinar la relación entre la política monetaria y la fragilidad financiera se hace en dos etapas. La primera pretende comprender la dinámica de las variables incluidas en el modelo, y para ello se hace uso de Vecto- 
res AutoRegresivos (VAR). La segunda pretende estimar una forma estructural del modelo y se utiliza el Método Generalizado de Momentos.

\subsubsection{Modelo VAR}

La dinámica entre las decisiones de política monetaria, el ciclo económico, los flujos de capital y la estabilidad financiera se modela a través de un VAR, que se puede identificar a través de la siguiente ecuación:

$$
\mathrm{Y}_{\mathrm{t}}=\mathrm{D}_{\mathrm{t}}+\sum_{i=1}^{m} \sum_{j=1}^{r} \beta_{j} \mathrm{Y}_{t-i}+\mu_{t}
$$

Definidas las diferentes variables endógenas () es necesario especificar cada una de las variables en función de los valores rezagados y de los rezagos de las demás variables (), y para ello se considera un componente determinista () y otro de error (), Por tanto, el vector de variables endógenas es:

$$
Y_{t}=\left[\begin{array}{c} 
\\
t i b r \\
b p i b \\
c c \\
\text { dief }
\end{array}\right]
$$

En el modelo se desea representar cómo las decisiones de política monetaria se reflejan en las modificaciones de la tasa de interés de intervención del Banco de la República (tibr). El ciclo económico se representa a través de la brecha del producto (bpib), que se calcula como la diferencia entre el logaritmo natural del PIB real (precios de 2005) y la tendencia de largo plazo del PIB (estimada por medio del filtro de Hodrick-Prescott). Para entender los efectos de los choques externos se usa la participación del saldo de la cuenta financiera respecto al PIB (cc), donde esta muestra cómo las masivas entradas de capital al país pueden llevar a engendrar procesos de fragilidad financiera y salidas abruptas pueden conducir a problemas de balanza de pagos.

La estabilidad financiera se representa con el índice de estrés financiero, que como ya se señaló, cuando aumenta la inestabilidad financiera tiende a aumentar, y es definido en primeras diferencias para capturar las variaciones positivas y negativas de la fragilidad financiera (dief). 
Tabla 1. Descripción de variables ${ }^{10}$

\begin{tabular}{|l|l|l|c|}
\hline \multicolumn{1}{|c|}{ Variable } & \multicolumn{1}{|c|}{ Descripción } & \multicolumn{1}{c|}{ Fuente } & Período \\
\hline TIBR & $\begin{array}{l}\text { Tasa de intervención del Banco de } \\
\text { la República }\end{array}$ & Banco de la República & $1996-2012$ \\
\hline IEF & Índice de estrés financiero & Banco de la República & $1996-2012$ \\
\hline PIB & Producto Interno Bruto & DANE & $1996-2012$ \\
\hline CC & Cuenta financiera & $\begin{array}{l}\text { Balanza de Pagos. Banco de la } \\
\text { República }\end{array}$ & $1996-2012$ \\
\hline PM & $\begin{array}{l}\text { Inflación objetivo }(1999-2012)=1 \\
\text { No inflación objetivo=0 }\end{array}$ & Información general & $1996-2012$ \\
\hline
\end{tabular}

Fuente: elaboración propia

\subsubsection{Pruebas de validez del modelo}

Los datos tomados tienen frecuencia trimestral, entre 1996 y 2012, y es necesario probar si son estacionarios; es decir, mostrar que los shocks que inciden en las series son transitorios. La consecuencia de la estacionariedad es que existe un valor medio al cual la serie retorna después de una perturbación, la varianza no depende del tiempo y las funciones de autocorrelación convergen. Datos estacionarios implica que no tienen raíz unitaria" ${ }^{11}$ y para probarlo se toman las pruebas de Dickey-Fuller y de Phillips Perron. En el tabla 2 se evidencia que todas las variables son estacionarias, es decir, no existe evidencia de raíz unitaria, con excepción de la brecha del producto en la prueba de Dickey-Fuller.

Tabla 2. Pruebas de Raíz Unitaria

\begin{tabular}{|l|c|c|c|c|}
\hline \multirow{2}{*}{ Cuenta financiera } & \multicolumn{2}{|c|}{ Dickey-Fuller } & \multicolumn{2}{c|}{ Phillips Perron } \\
\cline { 2 - 5 } & Estadístico t & Probabilidad & Estadístico t & Probabilidad \\
\hline Brecha del producto & $-4,523884$ & 0,0005 & $-93,85661$ & 0,0001 \\
\hline tibr & $-3,146438$ & 0,0280 & $-2,972094$ & 0,0427 \\
\hline dief & $-3,68696$ & 0,0065 & $-3,659592$ & 0,007 \\
\hline
\end{tabular}

Fuente: elaboración propia

10 Los autores tienen disposición de entregar datos utilizados en las estimaciones de este artículo cuando los lectores los soliciten al e-mail: mauricio8827@ hotmail.com.

11 Para probar la existencia de raíz unitaria se define la ecuación de la variable en el tiempo así:; ahora si se resta en ambos lados se tiene: y si . Entonces, si la y si, siendo que si el proceso que se sigue no es estacionario porque . 
Con base a las series expuestas es posible estimar el VAR, y para esto se deben ordenar las variables de la más exógena a la menos exógena; es decir, se define cc en primer lugar por su carácter exógeno, seguida por la bpib, la tibr y dief. Ahora, se toman cuatro rezagos óptimos (definidos por las pruebas LR, Final Prediction Error y el criterio de información de Akaike) para la estimación del modelo, los cuales permiten un ajuste dinámico satisfactorio y una estimación eficiente, dado que producen un comportamiento de los residuos adecuado.

Para probar la idoneidad del modelo se recurre a probar la no existencia de correlación serial y la homocedasticidad. La prueba de homocedasticidad de White demuestra que las varianzas de los residuales de las cuatro ecuaciones son constantes, por lo cual se acepta la eficiencia de los estimadores. De otro lado, la prueba LM (Multiplicadores de Lagrange) apunta a la inexistencia de correlación serial hasta el octavo rezago. En conclusión, el modelo VAR estimado es adecuado, dado que los residuos tienen un comportamiento consistente con ruido blanco y la estructura de rezagos es estable.

Tabla 3. Prueba de Homocedasticidad

\begin{tabular}{|c|c|c|c|c|c|}
\hline \multicolumn{6}{|c|}{ VAR Residual Heteroskedasticity Tests: No Cross Terms (only levels and squares) } \\
\hline \multicolumn{3}{|c|}{ Joint test: } & & & \\
\hline Chi-sq & $\mathrm{df}$ & Prob, & & & \\
\hline 347,2435 & 330 & 0,2465 & & & \\
\hline \multicolumn{6}{|c|}{ Individual components: } \\
\hline Dependent & R-squared & $F(33,27)$ & Prob, & Chi-sq(33) & Prob, \\
\hline resl*resl & 0,404854 & 0,556577 & 0,9452 & 24,6961 & 0,8506 \\
\hline res2*res2 & 0,379842 & 0,50113 & 0,9701 & 23,17035 & 0,8983 \\
\hline res3*res3 & 0,919024 & 9,285761 & 0 & 56,06043 & 0,0074 \\
\hline res4*res4 & 0,457539 & 0,690097 & 0,8456 & 27,9099 & 0,7186 \\
\hline res2*res1 & 0,383593 & 0,509158 & 0,9671 & 23,39915 & 0,8919 \\
\hline res3*resl & 0,617241 & 1,319411 & 0,232 & 37,65173 & 0,2647 \\
\hline res3*res2 & 0,647614 & 1,503652 & 0,1403 & 39,50445 & 0,2021 \\
\hline res4*resl & 0,524252 & 0,901597 & 0,6151 & 31,97936 & 0,5178 \\
\hline res4*res2 & 0,452726 & 0,676831 & 0,8578 & 27,61627 & 0,7321 \\
\hline res4*res3 & 0,67532 & 1,701781 & 0,0802 & 41,19451 & 0,1548 \\
\hline
\end{tabular}

Fuente: elaboración propia 
Tabla 4. Prueba de no correlación serial

\begin{tabular}{|c|c|c|}
\hline \multicolumn{3}{|c|}{ VAR Residual Serial Correlation LM Tests } \\
\hline \multicolumn{3}{|c|}{ Null Hypothesis: no serial correlation at lag order $h$} \\
\hline Lags & LM-Stat & Prob \\
\hline 1 & 13,37506 & 0,6452 \\
\hline 2 & 21,87241 & 0,1474 \\
\hline 3 & 10,85229 & 0,8185 \\
\hline 4 & 17,59875 & 0,3479 \\
\hline 5 & 15,66401 & 0,4766 \\
\hline 6 & 9,067883 & 0,9106 \\
\hline 7 & 16,13778 & 0,4434 \\
\hline 8 & 19,28453 & 0,2542 \\
\hline
\end{tabular}

Fuente: elaboración propia

\subsubsection{Causalidad de Granger y simulaciones}

Con el objeto de precisar la naturaleza de las relaciones se realizan las pruebas de causalidad de Granger, a través de las cuales es posible identificar la capacidad de pronóstico de una variable sobre otra. En el tabla 5 es posible denotar que existe una relación bidireccional entre la brecha del producto y la cuenta de capitales y financiera respecto al PIB, aunque la relación de la brecha del producto al flujo de capitales es débil (se rechaza la no causalidad a la Granger al 10\% de significancia mientras la relación contraria se rechaza al 1\% de significancia). La primera relación se justifica con el efecto del ciclo económico en la confianza de los extranjeros y su decisión de realizar inversiones en el país (IED, portafolio y deuda). La segunda relación muestra que los mayores flujos de capital contribuyen a que se expanda el ciclo económico y, de esa manera, para que se forme la burbuja financiera.

También se encuentra que la brecha del producto causa en el sentido de Granger a la postura de la política monetaria, debido a que la autoridad monetaria, a través de su tasa de política, responde a las fluctuaciones de la economía, siendo una brecha del producto positiva propulsora de procesos inflacionarios que deben ser amortiguados por medidas de política monetaria. Por último, la información de la cuenta financiera y de la postura de la política monetaria incide en las variaciones del índice de estrés financiero; la primera porque una expansión en la entrada de flujos de capital afecta el financiamiento del gasto interno, y cuando es excesivo el crecimiento del crédito puede redundar en procesos de inestabilidad financiera; y la segunda refleja la capacidad de la política monetaria para incidir en la estabilidad financiera de la economía colombiana, dado que decisiones de política monetaria 
Fragilidad financiera en Colombia y las decisiones de políitca monetaria del Banco de la República, 1996-2012

tienden a incidir en la calidad y cantidad de crédito otorgado y, de esa manera, en la estabilidad financiera.

Tabla 5. Causalidad de Granger

\begin{tabular}{|c|c|c|c|}
\hline \multicolumn{4}{|c|}{ VAR Granger Causality/Block Exogeneity Wald Tests } \\
\hline \multicolumn{4}{|c|}{ Sample: 199601 $2012 \mathrm{Q} 4$} \\
\hline \multicolumn{4}{|c|}{ Included observations: 61} \\
\hline \multicolumn{4}{|c|}{ Dependent variable: CC } \\
\hline Excluded & Chi-sq & df & Prob, \\
\hline BPIB & 7,481 & 4,000 & 0,113 \\
\hline TIBR & 1,258 & 4,000 & 0,868 \\
\hline DIEF & 1,620 & 4,000 & 0,805 \\
\hline All & 14,141 & 12,000 & 0,292 \\
\hline \multicolumn{4}{|c|}{ Dependent variable: BPIB } \\
\hline Excluded & Chi-sa & $d f$ & Prob, \\
\hline $\mathrm{CC}$ & 24,271 & 4,000 & 0,000 \\
\hline TIBR & 3,404 & 4,000 & 0,492 \\
\hline DIEF & 4,569 & 4,000 & 0,335 \\
\hline All & 33,371 & 12,000 & 0,00 \\
\hline \multicolumn{4}{|c|}{ Dependent variable: TIBR } \\
\hline Excluded & Chi-sq & $d f$ & Prob, \\
\hline $\mathrm{CC}$ & 0,645 & 4,000 & 0,958 \\
\hline BPIB & 19,658 & 4,000 & 0,000 \\
\hline DIEF & 1,649 & 4,000 & 0,799 \\
\hline All & 34,962 & 12,000 & 0,000 \\
\hline \multicolumn{4}{|c|}{ Dependent variable: DIEF } \\
\hline Excluded & Chi-sa & $d f$ & Prob, \\
\hline $\mathrm{CC}$ & 13,336 & 4,000 & 0,009 \\
\hline BPIB & 2,731 & 4,000 & 0,604 \\
\hline TIBR & 8,884 & 4,000 & 0,064 \\
\hline All & 40,485 & 12,000 & 0,000 \\
\hline
\end{tabular}

Fuente: elaboración propia con datos del Banco de la República (2014)

Con el análisis de la descomposición de la varianza es posible identificar la importancia de los shocks de las variables sobre un shock de otra variable después de un año (cuatro trimestres). En ese sentido, lo que se puede observar en el gráfico 4 es que el shock de la cuenta financiera respecto al PIB se explica en 6,6\% por el 
shock de la brecha del producto, pero la mayoría del efecto viene definido por su propio shock. De otro lado, el shock de la brecha del producto viene explicado, en su mayoría, por los propios shocks y en un $24,3 \%$ por un shock de flujos de capital, siendo esto evidencia del impacto de los flujos netos financieros en el ciclo económico.

Gráfico 4. Descomposición de la varianza (cuarto rezago)

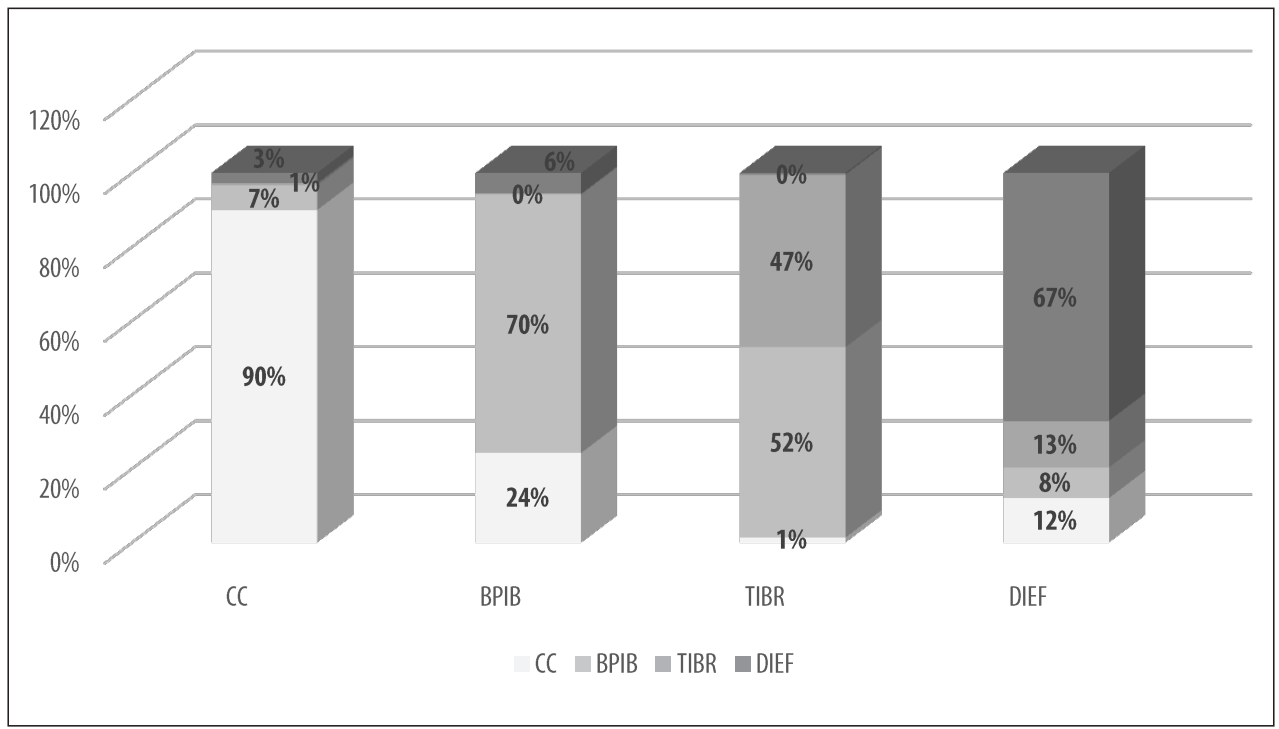

Fuente: figura adaptada de la presentación de Tenjo (2013)

Con el análisis de la descomposición de la varianza es posible identificar la importancia de los shocks de las variables sobre un shock de otra variable después de un año (cuatro trimestres). En ese sentido, lo que se puede observar en el gráfico 4 es que el shock de la cuenta financiera respecto al PIB se explica en 6,6\% por el shock de la brecha del producto, pero la mayoría del efecto viene definido por su propio shock. De otro lado, el shock de la brecha del producto viene explicado, en su mayoría, por los propios shocks y en un $24,3 \%$ por un shock de flujos de capital, siendo esto evidencia del impacto de los flujos netos financieros en el ciclo económico.

Es posible evidenciar que un shock en el ciclo económico explica en $51 \%$ el cambio inesperado de la postura de la política monetaria, por lo que las sorpresas en las fluctuaciones económicas llevan a una fuerte respuesta de la junta directiva de la autoridad monetaria. Un último aspecto es cómo el shock de inestabilidad financiera se justifica en 12,6\% por los shocks en las decisiones de política monetaria 
y en $12,1 \%$ por el shock en la cuenta financiera. Este resultado prueba que cuando el Banco de la República reacciona a una desviación del pronóstico de la inflación respecto a la meta la estabilidad financiera se ve afectada.

Por último, es necesario entender la respuesta dinámica a los shocks de política a través de las funciones Impulso-Respuesta, las cuales son posible de interpretar como la diferencia entre el valor esperado de una variable en el periodo , que resulta de una perturbación ocurrida en el periodo t, y el valor esperado en el periodo cuando hay ausencia de esa perturbación. Es de aclarar que estos valores esperados se derivan de la historia ya conocida en el periodo, En el gráfico 3 se evidencia, en primer lugar, que el ciclo económico tiene una respuesta positiva al comportamiento de la cuenta de capitales y financiera, donde el máximo efecto se refleja después de un año del surgimiento del shock de los flujos financieros, y desaparece hasta dos años y medio después; dicha respuesta ocurre porque la inversión financiada con recursos externos jalona el crecimiento de diferentes sectores de la economía, en especial al sector minero-energético.

El ascenso inicial en la brecha del producto generada por el shock de flujos de capital comienza con un incremento en la estabilidad financiera, debido a que inicia con un aumento en la calidad de la cartera del sistema financiero que luego se deteriora por los progresivos incumplimientos en los pagos. El retroceso de la estabilidad financiera ocurre después del tercer trimestre, y a partir de ese momento el proceso de fragilidad financiera se profundiza hasta después de dos años y medio cuando se agota el efecto.

La expansión del ciclo económico lleva a la autoridad monetaria a asumir una postura contractiva, siendo una reacción inmediata a la desviación del producto respecto a su nivel potencial, endureciéndose a medida que pasa el tiempo para evitar todo brote inflacionario, con un nivel máximo de contracción después del quinto trimestre, y luego se suaviza cuando comienza a volver la brecha del producto a cero. El efecto sobre la estabilidad financiera se evidencia a penas se da la contracción monetaria, pero se acelera a medida que aumenta la cartera vencida, la caída en la rentabilidad de los bancos, etc; lo anterior tiene su máxima respuesta después del segundo trimestre, pero se desvanece poco a poco en el tiempo. En síntesis, la autoridad monetaria responde a la brecha del producto con propósitos anti-inflacionarios, pero no responde en momentos en que se engendra la fragilidad financiera, por lo que toda expansión alivia la liquidez y acelera el crecimiento del crédito, pero cuando llega la contracción el estrés financiero aumenta, y sí se ha alimentado por mucho tiempo la burbuja tendrá como resultado una crisis financiera. 
Gráfico 5. Funciones Impulso-Respuesta (datos trimestrales)

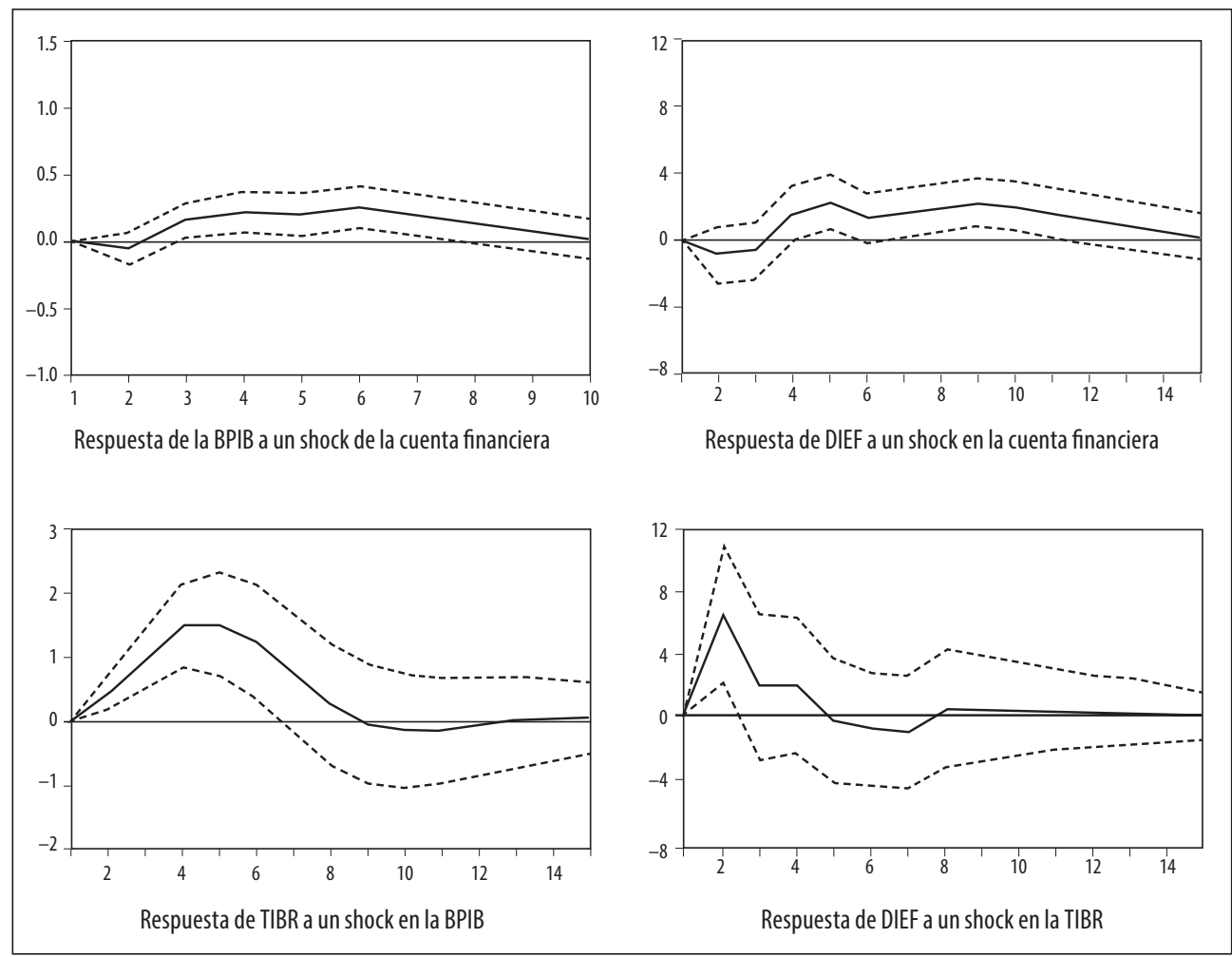

Fuente: elaboración propia con Eviews 6,0

\subsubsection{Estimación estructural}

La dinámica de los datos llevó a comprender que las decisiones de política monetaria tienen una relación con el comportamiento de la fragilidad financiera, y autores como Tenjo y otros (2013) y Adrian y Shin (2008) muestran que la tasa de política monetaria puede afectar variables asociadas al índice de estrés financiero. Por tanto, la ecuación que se deduce de acuerdo a la literatura expuesta y al entendimiento de la dinámica de los datos es:

$$
\operatorname{dief}_{t}=\beta_{0}+\beta_{1} t i b r_{t}-\beta_{2} b p i b_{t}+\beta_{3} c c_{t}+\beta_{4} \operatorname{dief}_{t-1}+\gamma p m_{t}+\mu_{t}
$$

En la ecuación se refleja que la variación en el estrés financiero depende de la tasa de política monetaria con signo positivo, debido a que una política monetaria contractiva puede evitar la profundización de la toma excesiva de riesgos por parte de los deudores cuando ocurre un ascenso en el costo de apalancamiento. Como 
ya se comprendió, la asociación directa entre el ciclo económico y la fragilidad financiera, se puede deducir que toda expansión económica lleva a que el estrés financiero sea más bajo que cuando ocurre una contracción. Desde el frente externo, siguiendo el planteamiento de Reinhart y Rogoff (2011), se pueden acelerar los procesos de inestabilidad financiera a través de los flujos de capital que financian el apalancamiento de diferentes sectores de la economía, y por contabilidad de balanza de pagos un excedente de cuenta financiera implica un déficit de cuenta corriente, demostrándose que una expansión del gasto es financiada con recursos externos.

Es necesario denotar que el comportamiento del estrés financiero sigue un proceso inercial, y es por esta razón que en momentos de crisis financiera surge un efecto bola de nieve que la lleva a profundizar en el tiempo (vulnerabilidad financiera deteriora la confianza, se contrae el crédito, se llega a la crisis financiera, se profundiza la vulnerabilidad financiera, etc). Por último, se incluye una variable () que distingue las diferencias, medidas con el coeficiente, en la fragilidad financiera después y antes de implementado el esquema de inflación objetivo.

La estimación econométrica se realiza con el Método Generalizado de Momentos (MGM) y no con el método tradicional de Mínimos Cuadrados Ordinarios (MCO), debido a que el proceso inercial lleva a que surja el problema de endogeneidad, que lleva a los estimadores a ser no consistentes. Para encontrar el estimador de MGM se hace uso de las condiciones de ortogonalidad y, además, para corregir la autocorrelación de residuos se utiliza la variable Newey-West y se determina un estimador de Kernel con pre-whitening. Esto último requiere de tres etapas. En la primera se estima un VAR que lleva a eliminar la dependencia temporal, en la segunda se estima la varianza asintótica de la media muestral de acuerdo a los residuos del VAR, y en la tercera se aplica el pre-whitening.

En la estimación se utilizan como variables instrumentales a las variables del modelo rezagadas durante 6 trimestres. En el tabla 6 se evidencia que los resultados son estadísticamente significativas y reflejan el marco teórico expuesto. En ese sentido, en la economía colombiana todo ascenso de la tasa de interés de intervención lleva a que el estrés financiero sea más bajo, debido a que se contrae el crecimiento del crédito y disminuye la probabilidad de incumplimiento.

El efecto del ciclo económico sobre el estrés financiero es negativo y lleva a señalar que un crecimiento económico por debajo del crecimiento potencial induce al surgimiento de síntomas de inestabilidad financiera; por tanto, resulta probable que descensos en la economía vengan asociados a problemas en la calidad de la cartera del sector financiero. De otro lado, se evidencia la relación positiva entre los flujos de capital y el estrés financiero, lo cual lleva a considerar que un déficit 
de cuenta corriente tiende a impulsar la formación de escenarios de inestabilidad en el sistema financiero. Lo comprobado de manera empírica para Colombia es lo señalado por Reinhart y Rogoff (2011). Finalmente, el signo negativo de lleva a comprobar que después de implementada la estrategia de inflación objetivo los escenarios de inestabilidad financiera han sido menores, que es coherente con la reflexión realizada por Bernanke, Gertler y Gilchrist (1998).

\section{Tabla 6. Regresión por el MGM}

\begin{tabular}{|c|c|c|c|c|}
\hline \multicolumn{5}{|c|}{ Method: Generalized Method of Moments } \\
\hline \multicolumn{5}{|c|}{ Kernel: Bartlett, Bandwidth: Variable Newey-West (24), Prewhitening } \\
\hline \multicolumn{5}{|c|}{ Simultaneous weighting matrix $\mathcal{E}$ coefficient iteration } \\
\hline \multicolumn{5}{|c|}{ Convergence not achieved after: 499 weight matrices, 500 iterations } \\
\hline \multicolumn{5}{|c|}{ Instrument list: $\mathrm{TIBR}(-1 \mathrm{TO}-6) \mathrm{BPIB}(-1 \mathrm{TO}-6) \mathrm{CC}(-1 \mathrm{TO}-6) \operatorname{DIEF}(-2 \mathrm{TO}-6)$} \\
\hline Coefficient & Val. Coefficient & Std. Error & t-Statistic & Prob. \\
\hline & $-0,214524$ & 0,028610 & $-7,498357$ & 0,000 \\
\hline & 0,692662 & 0,128616 & 5,385523 & 0,000 \\
\hline & $-4,815208$ & 0,831941 & $-5,787923$ & 0,000 \\
\hline & 7,926521 & 0,997334 & 7,947708 & 0,000 \\
\hline & 0,625113 & 0,031751 & 19,68773 & 0,000 \\
\hline & $-0,126092$ & 0,027658 & $-4,558893$ & 0,000 \\
\hline R-squared & \multicolumn{4}{|c|}{$-0,075828$} \\
\hline J-statistic & \multicolumn{4}{|c|}{0,061329} \\
\hline S.E. of regression & \multicolumn{4}{|c|}{0,207664} \\
\hline
\end{tabular}

Fuente: elaboración propia utilizando eviews 6.0

\section{CONCLUSIONES}

En este artículo se hizo un análisis acerca del papel que tuvo entre 1996 y 2012 la política monetaria colombiana en la estabilidad financiera. Un primer aspecto a tratar fue la distinción de cada una de las teorías sobre fragilidad financiera que permiten caracterizar cómo emergen los procesos de inestabilidad financiera; en ese sentido, se hizo una revisión de hechos que permitió identificar dos eventos de inestabilidad financiera, el primero en 1999 y el segundo durante la crisis financiera internacional de 2008. La característica fundamental de los dos hechos es que estos surgen por choques de carácter internacional, pero difieren en que durante el primero la economía interna presentaba síntomas de vulnerabilidad financiera y 
la política monetaria no tenía una operatividad que pudiera garantizar la estabilidad financiera, y en el segundo con un esquema de inflación objetivo consolidado y con distintas características de regulación financiera que llevó a la estabilidad sin mayores sacrificios.

En ese sentido, según lo analizado para la década de los noventa desde varios frentes se engendró la fragilidad que llevaría a la recesión de fin de siglo. Un primer aspecto es el surgimiento de la bonanza, que a principios de la década se alimentó con flujos financieros provenientes del extranjero que permitió la liquidez necesaria para expandir el crédito de consumo, comercial y de vivienda; donde el último tenia matices diferentes que se ligaba a una política pública que favorecía la adquisición de vivienda por parte de los hogares. Un segundo aspecto fue las políticas económicas inadecuadas, siendo que desde el frente fiscal surgió un déficit fiscal creciente que amenazaba con tener incidencias en el crecimiento económico; y desde el frente de política monetaria se evidenció unas posturas inadecuadas, debido a que en 1997 con la desaceleración se dieron expansiones en los agregados monetarios que sostuvo la burbuja, pero con la parada súbita de 1998 y la posterior defensa de la banda cambiaria se agotaron las reservas internacionales, y, además, con una inflación creciente el Banco de la República tuvo que adoptar una postura contractiva, pero cuando en 1999 quiere que sea contraria no logra expandir la liquidez lo suficiente.

La desaparición de un objetivo de intervención cambiaria, la definición de un marco regulatorio al sistema financiero más estricto y la adopción del esquema de inflación objetivo llevó a que la política monetaria tuviera una operatividad más clara y direccionada a la reducción de la volatilidad de la inflación. En ese sentido, cuando en 2008 surge un nuevo escenario de estrés financiero que proviene de un entorno internacional inestable, Colombia se encuentra expuesta a través de una expansión del crédito con un aumento de la cartera vencida, pero al existir un marco regulatorio diferente al de los noventa y con una política monetaria con tendencia a ser contractiva fue posible llevar la cartera vencida a niveles normales.

Lo anterior fue posible entenderlo a través de un esquema que define el mecanismo de transmisión, donde el canal del crédito resulta esencial para conectar las decisiones de política monetaria y la estabilidad financiera; por tanto, bajo dicho argumento se estimó un modelo VAR y una forma estructural mediante el MGM que permitió relacionar las decisiones de política monetaria, el ciclo económico, la dinámica de los flujos de capital con el estrés financiero. La estimación permitió dejar claro que los shocks de flujos de capital tienen una fuerte incidencia en el ciclo económico y en la estabilidad financiera, y la postura de la autoridad monetaria ha determinado la dinámica de la fragilidad financiera; esto permite obtener la hipótesis 
de que el Banco de la República cuando ha tomado decisiones de contracción monetaria lo ha hecho en momentos en que la economía ya tiene una alta vulnerabilidad financiera, y lo que ocasiona es una profundización del problema.

Por tanto, según Gil (2015) las lecciones que deja la crisis internacional es que la política tradicional se debe complementar con medidas de corte macro-prudencial, donde las autoridades direccionen los instrumentos de regulación de la misma forma como el banco central opera los cambios en la tasa de interés y, además del crédito, se deben observar variables como la creciente dinámica de los flujos internacionales de capital de corto plazo y los precios de los activos.

\section{BIBLIOGRAFÍA}

Adrian, Tobias y Hyun Song Shin (2008). Financial Intermediaries, Financial Stability, and Monetary Policy. En: Federal Reserve Bank of New York, Staff Reports, No 346.

Arestis, P. y Glickman, M. (2002). Financial Crisis in Southeast Asia: Dispelling Illusion the Minskyan Way. En: Cambridge Journal of Economics, 26, p. 237-260

Bernanke, Ben; M. Gertler y S. Gilchrist (1998). The Financial Accelerator in a Quantitative Business Cycle Framework. En: NBER Working Papers No 6455.

Borio, C. y P. Lowe (2002). Asset Prices, Financial and Monetary Stability: Exploring the Nexus. En: BIS Working Paper, No 114.

Caballero, R y Krishnamurthy, A (2000). Emerging Market Crises: An Asset Markets Perspective. En: Cambridge - NBER Working Paper 6843.

Calvo, Guillermo A. y Enrique Mendoza (1996). Reflections on Mexico's Balanceof Payments Crisis: A Chronicle of a Death Foretold. En: Journal of International Economics, Vol, 41 (Noviembre), p. 223-34.

Cárdenas, Mauricio; A, Badel (2003). La Crisis de Financiamiento Hipotecario en Colombia: Causas y consecuencias. En: Documento de trabajo, No 500, Banco Interamericano de Desarrollo.

Castro, Juan Carlos (2011). Fragilidad Financiera y Tasa de Cambio. En: Revista Cuadernos de Economía, No 55, Universidad Nacional de Colombia, p. 155-177.

Cerón Cruz, Juan Antonio (2008). Crisis financieras internacionales, teorias explicativas y propuestas de reforma del Sistema Monetario: el caso de las subprime. X reunion de Economia Mundial, Barcelona.

Echavarría, Juan José; Andrés González; y Norberto Rodríguez (2012). Choques Internacionales Reales y Su Impacto en la Economía Colombiana. En: Revista Ensayos Sobre Política Económica, Vol. 30, No 69, Banco de la República. 
Fragilidad financiera en Colombia y las decisiones de política monetaria del Banco de la República, 1996-2012

Echeverry, Juan Carlos (2001). Memorias de la recesión de fin de siglo en Colombia: flujos, balances y política anti-cíclica. Economía colombiana, Boletines de Divulgación, No 7, DNP Colombia.

Fernández, Andrés (2003). Reformas Estructurales, Impacto Macroeconómico y Política Monetaria en Colombia. En: Revista Desarrollo y Sociedad, Universidad de los Andes, marzo de 2003, p. $55-128$.

Flood, R. Y Garber, P. (1984). Collapsing exchange rate regimes: some linear examples. En: Journal of International Economics, No17, p. 1-13.

Gil, José Mauricio (2015). Relación entre política monetaria y estabilidad financiera: un análisis aplicado para Colombia. En: Revista Ensayos Sobre Política Económica, Vol. 33 No 77, Banco de la República, p. 133-148.

Gil, José Mauricio (2010). Una evidencia empírica en Colombia de la relación entre el mercado de activos financieros y la economía real. En: Revista Apuntes del Cenes No 49, Universidad Pedagógica y Tecnológica de Colombia (UPTC), p. 95-122.

González, Jorge Iván (1999). Ajuste macro, política monetaria y empleo. En: Revista Nomadas, documento presentado en la mesa de empleo.

Hernández, A. y J. Tolosa (2001). La Política Monetaria en Colombia en la Segunda Mitad de los Años Noventa. En: Borradores de Economía, No 172, Banco de la República.

Kalecki, M. (1956). Teoría de la Dinámica Económica: Ensayo Sobre los Movimientos Cíclicos y a Largo Plazo de la Economía Capitalista. México, FCE.

Kindleberger, C.P. (1989). Manías, pánicos y cracs, Historia de las crisis financieras. Barcelona, Ed: Ariel.

Kiyotaki N. y Moore, J. (1997). Credit Cycles. En: Journal of Political Economy, Vol, 105 No, 2, p. 211-248.

Kregel, J.A. (1998). Yes, It Did Happen Again - A Minsky Crisis Happened in Asia. En: Jerome Levy Economics Institute Working Papers No, 234, New York, Jerome Levy Economics Institute. Krugman, Paul (1999). Balance Sheets, the Transfer Problem and Financial Crises. En: International Tax and Public Finance, No 6, p. 459-472.

Krugman, Paul (1979). A model of balance-of-payments crises. En: Journal of Money, Credit and Banking, Vol, 11, No 3, p. 311-325.

Kurczyn B, Sergio (1997). Probabilidad, incertidumbre y especulación en Keynes: Evolución y Actualidad.

López Enciso, Enrique y Andrés Salamanca Lugo (2009). El efecto riqueza de la vivienda en Colombia. En: Borradores de economía, No 551, Banco de la República. 
Melo, Jimmy (2012). La Hipótesis de Inestabilidad Financiera de Minsky en Una Economía Abierta. En: Ensayos de Economía, No 41, Mexico.

Mies, Verónica; Felipe Morandé; Matías Tapia (2003). Política monetaria y mecanismos de transmisión: nuevos elementos para una nueva conclusión. En: Centro de Estudios Monetarios Lationamericano (CEMLA), Mexico D.F.

Minsky, Hyman (1982). Can It Happen Again? Essays on Instability and Finance, New York, ed. Sharpe.

Mishkin, Federic (2007). Consensos Actuales en Política Monetaria: entre el arte y la ciencia. En: Revista Cultura Económica, Vol 70, p. 44-65,

Modigliani, Franco y Merton Miller (1958). The cost of capital, corporation finance and the theory of investment. En: American Economic Review, Vol. 48, No 3, pp. 261-297.

Ocampo, Jose Antonio (2003). Capital-account and countercyclical prudential regulations in developing countries. En: CEPAL Serie Informes y Estudios Especiales, No 6.

Obstfeld, M, (1996). Models of currency crises with self-fulfilling features. En: European Economic Review, No 40, p. 1037-1047.

Reinhart, Carmen y Kenneth Rogoff (2011). Esta Vez es Distinto: Ocho Siglos de Necedad Financiera. México, Fondo de Cultura Económica, Princenton University, 464p.

Reinhart, Carmen y Vincent Reinhart (2009). Bonanzas de Flujos de Capital: Una Política que Abarca el Pasado y Presente. En: Ensayos Sobre Política Económica, vol. 27, No, 59, Banco de la República.

Schinasi, Garry J. (2005). Preservación de la Estabilidad Financiera. En: Serie de Temas de Economía, No 36, Fondo Monetario Internacional.

Tenjo, Fernando (2013). Dinámica del Crédito y Política Monetaria en Colombia. Conferencia por el lanzamiento de la revista Apuntes del Cenes No 54, UPTC.

Tenjo Galarza, Fernando; Luisa F Charry V; Martha López P y Juan M Ramírez C (2007). Acelerador Financiero y Ciclos Económicos en Colombia: Un Ejercicio Exploratorio. En: Borradores de Economía, No 451, Banco de la República.

Zárate, Juan Pablo; Adolfo León Cobo Serna; y José Eduardo Gómez González (2012). Lecciones de las crisis financieras recientes para el diseño e implementación de las políticas monetarias y financieras en Colombia. En: Revista Ensayos Sobre Política Económica, Vol. 30, No 69, Banco de la República, p. 257-293. 